\title{
Reiterar, adaptar, negociar: Sobre un reglamento para los hospitales de Cuba (1776)
}

\author{
por:
}

\author{
Adriana María Alzate Echeverri \\ Universidad del Rosario, Bogotá \\ adriana.alzate@urosario.edu.co
}

\begin{abstract}
El artículo estudia el Reglamento para el gobierno interior, político y económico de los hospitales reales, que se estableció primero para Cuba y luego para toda la América española en 1776. Este documento es clave para comprender algunos de los proyectos que la Corona española tuvo con la institución hospitalaria en las Indias. El Reglamento buscaba proporcionar una estructura general dentro de la cual se desarrollaran las actividades administrativas, médicas, de cuidado, alimentación y asistencia espiritual dentro del hospital, al tiempo que reiteraba normas ya existentes, con un nuevo acento e intensidad. Pretendia, asimismo, ayudar a resolver una serie de litigios y debates que se presentaban entre diversos grupos sociales sobre cómo debería funcionar el establecimiento.
\end{abstract}

Palabras Clave: Historia de Cuba; siglo XVIII; hospitales coloniales; medicina y asistencia; salud pública.

El Reglamento para el gobierno interior, político y económico de los hospitales reales, que se estableció en principio para Cuba y posteriormente para toda la América española en 1776, constituye un documento clave para comprender algunos de los proyectos que la Corona española tuvo en relación con la institución hospitalaria en las Indias. El Reglamento buscaba suministrar una estructura general dentro de la cual se desarrollaran las actividades hospitalarias, al tiempo que reiteraba normas que ya existían, con un nuevo acento (fijaba el personal que allí trabajaría, el empleo del tiempo, la manera de realizar ciertos tratamientos, algunos regímenes alimenticios). Pretendía, 
asimismo, ayudar a resolver una serie de controversias y debates que se presentaban entre diversos grupos de la sociedad cubana de entonces, sobre cómo debería funcionar el establecimiento, proponiendo, al mismo tiempo, formas de resolver las contiendas y abusos ${ }^{1}$.

\section{El HOSPITAL, CRISOL DE INTERESES Y CONFLICTOS}

Durante el siglo XVIII, la institución hospitalaria fue objeto de múltiples polémicas, lugar de tensiones y de rivalidades suscitadas por intereses diversos. Desde diferentes ámbitos, el hospital aparecía como un establecimiento ineficaz, problemático, que necesitaba transformaciones.

En tal sentido, desde el punto de vista económico ante las urgencias de la Monarquía española, se pretendía que el hospital contribuyera a la recuperación de brazos útiles para el trabajo, la producción y el ejército. Para ello, era preciso que participara de manera más efectiva en la recuperación de la salud de la población. Las autoridades metropolitanas buscaban actuar de manera enérgica en la vida hospitalaria, tal intervención estaba hondamente vinculada con las políticas ilustradas de los borbones frente a la pobreza y la sanidad y con la utilización estratégica de los recursos derivados del ejercicio de la piedad cristiana ${ }^{2}$.

Aunque los ritmos, funciones y transformaciones de la institución no fueron exactamente similares para todas las regiones de la Monarquía hispánica, ni para todo el mundo Occidental, sí es posible identificar el malestar que la institución producía en varios grupos sociales del mundo colonial americano durante el siglo XVIII.

En el siglo XVIII, la política hospitalaria borbónica aspiraba a dar una estructura distinta e instaurar un funcionamiento preciso, metódico, sistemático en la institución, tanto en España como en sus colonias americanas, para que pudiera vincularse en forma eficaz con la disminución de la pobreza y el crecimiento poblacional y económico. La enfermedad y la pobreza eran considerados los principales frenos para el progreso y riqueza de España, por

\footnotetext{
${ }^{1}$ Se trata del Reglamento para el gobierno interior, politico y económico de los hospitales reales, erigidos en la isla de Cuba, con destino a la curación de las tropas, forzados, y negros esclavos de S.M., según las circunstancias, temperamento, y costumbres del país. Formado por el señor Don Nicolás Joseph Rapún, impreso en Madrid en 1776.

${ }^{2}$ Los motivos para la asistencia a los pobres y enfermos tampoco era nuevos. El cuidado de la salud más que buscar la redención y la rehabilitación de los mendigos y vagabundos, fue visto por la dinastía Habsburgo como un recurso con fines ideológicos y políticos. HuguetTermes, 2009: 65. Ver, asimismo, en este sentido: De los Reyes Leoz, 2003: 34.
} 
ello se habían convertido en uno de los blancos prioritarios de la Monarquía. El hospital debía ser un efectivo instrumento terapéutico, de intervención en la enfermedad y el enfermo, de curación ${ }^{3}$. En teoría, la institución tenía muchas funciones, aunque, como se dijo, no hubo nunca homogeneidad en cuanto a sus tareas y al ritmo de sus transformaciones en el mundo hispanoamericano. El hospital fue asilo para indigentes, albergue de peregrinos, sanatorio para enfermos y convalecientes, lugar de reparto de limosnas a mendigos, teatro de la medicina, filtro de seguridad para extranjeros-mendigos y transeúntes, control de la política sanitaria local (epidemias), agente en la política urbanística de las grandes ciudades (alquiler de casas), entre otras. Así, estas funciones hacen del hospital una de las claves de las «políticas sociales» en el Antiguo Régimen ${ }^{4}$.

En una perspectiva política, la institución producía disgustos y roces entre el poder religioso y el civil, derivados de las dinámicas impuestas por el Real Patronato. La orientación regalista de la monarquía borbónica, esperaba frenar la notable ascendencia económica, política, social y sanitaria del estamento religioso en la sociedad de entonces ${ }^{5}$.

Desde finales del siglo XVII, España necesitaba, entre otras cosas, crear un sistema relativamente estable, no sólo para la recepción de los saberes modernos, sino también para su transmisión a través de diferentes instituciones. Debería poder integrarlos a la producción, tanto en la práctica institucional -hospitalaria, universitaria, municipal o náutica- como en la industrial -manufacturas y oficios-. Ingenieros, médicos, cirujanos, cartógrafos, cosmógrafos consiguieron que las grandes ciudades españolas del dieciocho vivieran una agitación vinculada con el desarrollo de esas actividades ${ }^{6}$. Además, entre los objetivos de la reforma sanitaria borbónica estaba transformar la enseñanza de la medicina y la práctica de la cirugía, para lo cual la reestructuración del hospital era esencial.

El contexto general en el cual se inscribe este proceso de reforma hospitalaria puede caracterizarse, sumariamente, en el ámbito de una historia de las ideas y las sensibilidades, por el cambio en la actitud del hombre hacia la naturaleza, que se traducía en una afirmación del poder humano para orientar sus fuerzas, en lugar de aceptar con resignación los sucesos que ella desencadenaba; en una alteración de la fatalidad tradicional hacia la enfermedad y la muerte. La creencia en la posibilidad de dominar la naturaleza por medio de la

\footnotetext{
3 Foucault, 1978: 20.

${ }^{4}$ De los Reyes Leoz, 2003: 35-36.

${ }^{5}$ Alzate Echeverri, 2012b: 195.

${ }^{6}$ Lafuente y Valverde, 2003: 7.
} 
ciencia, y el deseo de ponerla al servicio de los hombres, comienza a generar un saber que servirá para la instauración de prácticas médicas, que pretendían detener la desaparición de poblaciones a causa de la enfermedad, conservar la salud y actuar sobre la duración de la vida ${ }^{7}$. A estos intereses se unen también la apelación a uno de los aspectos más importantes del pensamiento ilustrado: la felicidad, que aparece aquí en su justa medida, en relación con la salud ${ }^{8}$. Esas nuevas actitudes fundarán una parte de los discursos relativos a la salud, la asistencia y el hospital en Europa y en América hispánica9

Paralelamente, surgen, en la sociedad europea occidental, las teorías poblacionistas, que conciben la población como «recurso fundamental». La insistencia en una población densa fue uno de los objetivos más importantes en los países europeos, desde finales del siglo XVII y durante el siglo XVIII ${ }^{10}$. Esa preocupación promovió la idea de mejorar una serie de métodos que generaran un saber sobre las características de la población y sobre los problemas de los cuales debían ocuparse los gobiernos, con el fin de actuar más eficazmente sobre ella y hacerla más productiva ${ }^{11}$.

De este modo, comienza a desarrollarse un conjunto de saberes sobre el comportamiento humano ${ }^{12}$, varios aspectos biológicos de la población comenzaron a volverse pertinentes para la gestión económica de la sociedad, y se hizo necesario organizar alrededor de ellos estrategias que aseguraran su sujeción y su productividad. Estas profundas transformaciones culturales en relación con la naturaleza, la vida, la población y la producción tuvieron también influencia en la imagen de la medicina, pues aumentaron su presencia, cambiaron sus modos de intervención y determinaron la manera de prevenir o limitar las enfermedades ${ }^{13}$.

En América Hispánica, específicamente y en proporciones diversas según el territorio del cual se tratare, los hospitales debieron afrontar la presión

${ }^{7}$ Roche, 1993: 438. Vigarello, 1985: 155.

${ }^{8}$ Risse, 1992: 151.

9 Alzate Echeverri, 2012b: 195.

${ }^{10}$ La idea de que la capacidad de un Estado para conseguir riqueza y poder dependía mucho de su potencial demográfico - basada en una creencia de raíz mercantilista-, permitió que durante el siglo XVIII la salud y la enfermedad comenzaran a ser pensadas como problemas políticos y económicos, que debían tratarse en forma colectiva. Durante el siglo XVIII muchos pensadores ilustrados, de diferentes países de Europa, propusieron formas de intervención en el medio físico y social que buscaban elevar el nivel de salud de las poblaciones, planteando, que la ejecución de esas medidas era responsabilidad del poder político. España no fue ajena a esta tendencia. Jori, 2012: 1-29.

${ }^{11}$ Foucault, 1984: 201.

12 Idem.

13 Vigarello, 2001: 29-30. 
que creó el aumento de la demanda de sus servicios en el siglo XVIII. Esto se debió, principalmente, al aumento de la población de los virreinatos, y al crecimiento urbano producto de las migraciones en algunas regiones más que en otras. En Cuba, el aumento de la población se hizo muy evidente desde 1775 , debido a la crecida espectacular del ingreso de esclavos ${ }^{14}$. También fue significativo en este contexto el fenómeno epidémico, pues ante éste los oficiales de la Corona y los pobladores se encontraron casi siempre desprovistos de adecuadas instituciones de asistencia ${ }^{15}$.

La reforma sanitaria borbónica traía consigo cambios, en especial en la enseñanza de la medicina y la cirugía. La Corona propuso la actualización de los conocimientos que se impartían en los centros docentes y la introducción de nuevas áreas del saber, en particular las de carácter «útil» y práctico. Se realizó una revisión de los currículos universitarios y se buscó actualizarlos con nuevas asignaturas, como la botánica, la cirugía, las matemáticas y la física, labor que se complementaría con la introducción de textos modernos. Al mismo tiempo, se trató de uniformar los planes de estudio de todas las universidades españolas ${ }^{16}$.

Por todo esto puede entenderse la importancia de un documento relacionado con los ideales de la política hospitalaria en los territorios americanos como lo fue, entre otros, el Reglamento para el gobierno interior, político y económico de los hospitales reales. Si bien desde los siglos XVI y XVII, la Corona española había dictado disposiciones para reglamentar la presencia y el funcionamiento de la institución hospitalaria en estos territorios, los aspectos anteriormente mencionados hacen que la importancia del hospital en el marco de la sociedad colonial, en el siglo XVIII, se acreciente.

Este conjunto de disposiciones, según la Real Orden del 22 de agosto de 1776, debía comunicarse a los territorios de Indias, «para la exacta observancia de todos sus artículos, en cuanto sean adaptables con la isla ${ }^{17}$. Varias de las constituciones o de los planes de reforma de hospitales establecidos en distintas ciudades coloniales como Cartagena de Indias y Santafé (Nueva Granada) ${ }^{18}$,

14 Naranjo Orovio, 2009: 30-31.

15 Alzate Echeverri, 2012: 43b.

16 Peset, 1988: 20-21.

17 Reglamento para el gobierno interior..., 1776: 2.

18 Según Fray Miguel Isla, durante la visita que realizó al Hospital San Juan de Dios de Cartagena en 1788, este Reglamento era el modelo que debería guiar al personal del hospital. Y a juzgar por el relato del virrey de la Nueva Granada, Mendinueta (1798), -en el cual solicita al Rey que se le permitiera ocupar a los militares como empleados del hospital-, era este Reglamento el que se observaba, desde sus inicios, en el Hospital Militar de Cartagena, 1798, Archivo General de Simancas, Simancas, Secretaría de Guerra, 7071, exp. 18, fols. 111r-112r. 
México y Veracruz (Nueva España) ${ }^{19}$ y Guatemala ${ }^{20}$, consagran las normas del Reglamento, a veces de manera casi idéntica y otras veces reescribiéndolas, adaptándolas a las condiciones locales -según predicaba el mismo documento-, aunque no ha podido establecerse si el mismo fue efectivamente observado en dichas instituciones.

Cuba, el laboratorio de la Monarquía

¿Por qué instituir este Reglamento primero en la isla de Cuba? El objetivo de la Casa Borbón de convertir las Indias en territorios rentables y de ocuparse mejor de su defensa, llevó a conjugar las primeras acciones en la isla de Cuba, una vez que su principal puerto se vio liberado de los británicos. Su condición de isla caribeña permitió a la Corona ensayar allí las reformas necesarias en el intento de seguir el modelo colonial desarrollado por otras potencias europeas $^{21}$, como lo venía haciendo desde los primeros tiempos coloniales.

La Monarquía Católica ensayó en Cuba diversas reformas durante el período colonial. Dado el tamaño y la diversidad de los territorios españoles en América, la Corona rara vez legisló para todos ellos en conjunto, de manera general. Prefería obrar gradualmente, trabajar poco a poco, aprendiendo de las experiencias iniciales impuestas en lugares precisos y haciendo eco a las necesidades locales particulares ${ }^{22}$, para extender luego la legislación, una vez corregida o mejorada, a todos sus reinos de ultramar.

La toma de La Habana por los ingleses en la Guerra de los Siete Años determinó el establecimiento, por parte de la Corona española, de un plan de reformas administrativas, comerciales, fiscales y militares que tenían como objetivo afirmar su dominio imperial. Cuba fue escogida como lugar de ensayo de las primeras medidas reformistas y para ello fueron enviados ahí el Capitán General Conde de Ricla y el Mariscal Alejandro O'Reilly ${ }^{23}$. El primero, además de inspeccionar el estado de la administración de la isla, debía sugerir la manera de instaurar un plan de fortificaciones que convirtiera La Habana en una plaza inabordable. El segundo, en cambio, realizaría la reforma del

Asimismo, en el Cabildo de Santafé se solicitó al médico Antonio Froes que redactara un plan de alimentación para el Hospital San Juan de Dios de esa ciudad tomando como base -adaptando- el Reglamento de Cuba.

${ }_{19}$ Al respecto, ver Ranero Castro, 2003. Hernández-Sáenz, 2000: 21-35.

20 Belaubre, 2011: 2-3.

${ }^{21}$ González Ripoll-Navarro, 1999: 40-41.

${ }^{22}$ Kuethe e Inglis, 1985: 118-143. Ver también Santamaría García, 2009: 73-74.

${ }^{23}$ Kuethe, 1986. 
ejército y de las milicias, además de ejecutar una visita general a la isla para comprobar el estado de su economía. La parte más delicada de la misión de ambos fue negociar con la élite criolla una reforma fiscal que tenía como fin primordial la implantación de la alcabala, impuesto del cual se había eximido a los habitantes de la isla por especial privilegio desde el siglo XVI ${ }^{24}$. La reforma militar, encargada al mariscal de campo O'Reilly, sirvió de base a la del resto de las colonias ${ }^{25}$. Este Reglamento de los hospitales de Cuba aparece casi 10 años después de la reforma militar, pero no es mencionado por quienes se han ocupado de este tema, aunque formaba parte, sin duda, de esa aspiración innovadora de los borbones.

Las informaciones que O'Reilly y Ricla enviaron a la Corte en 1764, fueron también claves para la redacción del real decreto de octubre de 1765, que inició el establecimiento del sistema de «libre comercio» en América, y para la instauración de la primera intendencia de ejército y hacienda del Nuevo Mundo, la de La Habana ${ }^{26}$.

Por otro lado, el régimen de las intendencias, que también se ensayó en Cuba en 1764, transformó la administración local, provincial y central de las colonias. Con ellas se establecía en algunos virreinatos una especie de superintendente general que actuaba como jefe supremo de la hacienda pública, y que dependía directamente del Monarca, sustituyendo al virrey como ordenador general de pagos y en todas las funciones relacionadas con la hacienda pública. Se esperaba así que el superintendente unificase la administración de los fondos públicos y lograse su control efectivo. Hecho esto, debería también implantar numerosas reformas fiscales ${ }^{27}$.

Algo semejante sucedió con el estanco de tabaco, que se instauró oficialmente, primero en Cuba en 1717, pero ya había sido ensayado en $1708^{28}$. En junio de 1760 la Corona suprimió el monopolio que poseía la Real Compañía de La Habana respecto al traslado del tabaco cubano hacia España -y otros mercados- y asumió el control directo de la administración de la renta de tabaco en Cuba. Debido a que la Corona se había dado cuenta de las posibilidades que ofrecía la creciente demanda del producto, para conseguir un mayor beneficio controlando directamente el estanco ${ }^{29}$.

${ }^{24}$ Amores Carredano, 1996: 227.

${ }^{25}$ O’Reilly reorganizó el ejército regular y las milicias, creó varias compañías de infantería y de caballería, estableció un nuevo reglamento y un nuevo cuerpo de oficiales. Ver sobre este tema Vila Vilar y Kuethe, 1999. Kuethe, 1986.

${ }^{26}$ Idem.

27 Céspedes del Castillo, 1989, vol. 1: 168.

${ }^{28}$ González Ripoll-Navarro, 1999: 40-41.

29 Amores Carredano, 1999: 123. 
Cuba aparece así como una suerte de «laboratorio experimental», un lugar de ensayo, un territorio de prueba para varias de las reformas llevadas a cabo por Carlos III. Algo semejante sucede con las disposiciones relativas al traslado de los cementerios fuera de las ciudades y al intento de reforma de la institución hospitalaria, muy vinculada con las fuerzas armadas, como se apreciará en el siguiente apartado ${ }^{30}$.

\section{Nicolás José RAPÚN, Un MILITAR ILUSTRADO ${ }^{31}$}

En toda Europa, los cambios ilustrados pasaron por una modernización del ejército, que sirvió a la vez de productor y consumidor de saber científico. El ejército tuvo un papel cardinal porque su centralización, jerarquización y estabilidad le permitía ser utilizado en este sentido ${ }^{32}$. Es posible comprender la acción de un militar ilustrado y su presencia creciente en las actividades científicas durante la monarquía borbónica, porque al poseer conocimientos en diversas esferas del saber, el militar estaba en condiciones de proponer cómo organizar la sociedad, la ciudad o algunas instituciones ${ }^{33}$. En este proceso de militarización de la ciencia, los saberes médicos y, sobre todo, quirúrgicos, fueron muy importantes, pues se necesitaba formar cirujanos competentes para el Ejército y la Armada. En este contexto se revalorizaron prácticas como la cirugía, lo que tendrá mucha presencia en el Reglamento que se estudia ${ }^{34}$.

Nicolás Joseph Rapún, autor de este Reglamento, se formó a mediados del siglo XVIII, en un momento en el cual se llevaba a cabo un proceso germinal de institucionalización de la ciencia moderna en España, dentro del cual las instituciones militares desempeñaron un papel fundamental, promoviendo un nuevo rol social para los oficiales ilustrados ${ }^{35}$. Rapún nació en 1720, en Banastás (Aragón) y viajó muy joven a Madrid, donde inició su carrera en el cuerpo civil de la marina, en Cádiz, institución que vivía, en la época, un

${ }^{30}$ Sobre el papel de Joseph de Ezpeleta en este tipo de disposiciones, ver: Alzate Echeverri, 2007: 201-202.

${ }^{31}$ Debo la mayor parte de las informaciones que aquí consagro sobre Nicolás Joseph Rapún a la gentileza del profesor Juan Bosco Amores Carredano, del Departamento de Historia de la Universidad del País Vasco.

32 Lafuente y Peset, 1985: 127.

33 Ricuperati, 1997: 21.

${ }^{34}$ Ello se concretó en el importante apoyo monetario e ideológico que la Monarquía prestó a quienes que se encargaron de realizar esta tarea: los cirujanos mayores de la Real Armada Juan Lacomba y Pedro Virgili. Astrain Gallart, 1996: 136.

${ }^{35}$ Lafuente y Peset, 1985: 128. 
proceso de modernización. Luego empezó una carrera rápida y destacada. Durante la Guerra de la Oreja (1739-1748) fue tesorero en la escuadra de Andrés Reggio, que operó en el Caribe; luego regresó a Cádiz y, siendo oficial segundo de la contaduría principal de ese departamento marítimo, fue destinado, en 1752 y con el mismo empleo, a La Habana bajo las órdenes de Lorenzo de Montalvo, comisario ordenador de marina de esa plaza, para que supliera «las ausencias y enfermedades de aquel ministro» ${ }^{36}$.

En 1761, sin abandonar su puesto en la marina, fue nombrado interventor general de la recién restaurada Renta y Real Factoría de tabacos ${ }^{37}$, donde tuvo también, al parecer, una actuación eficaz. Al año siguiente se produjo el ataque inglés a La Habana y Rapún demostró su capacidad de organización en el aprovisionamiento de víveres y pertrechos para la defensa, y en el resguardo del producto y de los caudales de la Factoría. En 1763, tras la retirada inglesa, el conde de Ricla le nombró interventor general de las obras de fortificación, con responsabilidad también sobre los almacenes y los hospitales. Fue quizá entonces cuando se informó en detalle sobre la situación hospitalaria en esta isla.

Finalmente, en una lúcida y rápida carrera, Rapún redactó una «Instrucción general del cultivo de tabacos» de 1764, que pasa por ser el primer ensayo de este tipo producido en la América española ${ }^{38}$. En febrero de 1773 recibió el nombramiento como sustituto interino de Altarriba, y poco después se le nombró intendente de la isla, el 18 de enero de $1773^{39}$. Falleció de disentería, el 5 de marzo de 1776, tres años después de haber alcanzado la cumbre de su larga carrera ${ }^{40}$.

${ }^{36}$ Cuando llevaba sólo dos años en La Habana fue ascendido a comisario de guerra de marina, con el empleo de contador principal «de la fábrica de bajeles de esta Isla», Archivo General de Indias, Sevilla (AGI), Contratación, doc. 5495, N. 2, R. 38.

${ }^{37}$ Rapún fue el primero en ocuparlo. Rivero Muñiz, 1964, vol. I: 238.

38 Céspedes del Castillo, 1992: 107.

39 AGl, 24 de diciembre de 1772, Ultramar, O’Reilly a Arriaga, exp. 120.

40 AGI, 03 de marzo de 1776, Santo Domingo, Urriza a Arriaga, exp. 1654. Rapún murió soltero, pero dejó cinco hijos naturales, fruto de las relaciones con dos señoras habaneras de mediana posición. AGI, 18 de febrero de 1800, Ultramar, exp. 150, N. 33. Bernabé Rapún, comisario de guerra, hijo de Nicolás Rapún, intendente que fue de La Habana, solicitó una plaza en el tribunal de cuentas de aquella ciudad con honores de intendente de provincia. Reconoció a su primogénito, Bernabé, quien hizo una carrera brillante en el ministerio político del ejército y fue comisario de guerra. Para algunos aspectos de su vida familiar, ver: Lavrin, 1992: 141. 
La literatura producida en Europa sobre los hospitales fue cuantiosa en el siglo XVIII. Se conocieron, entre otras, obras como el plan del marqués de Condorcet (1743-1794), relativo a la gestión y a la organización administrativa de un proyecto hospitalario, fue escrito en $1786^{41}$; en ese mismo período Jacques Tenon había publicado sus Mémoires sur les hôpitaux de Paris (1788) y Pierre Georges Cabanis redactaba el importante texto Observations sur les hôpitaux (publicado en 1790). En Inglaterra se conoció la obra Thoughts on Hospitals (1771), de John Aikin y An Account of the Principal Lazarettos in Europe (1789), de John Howard ${ }^{42}$.

La gran organización hospitalaria inicial, en Europa, se encontró sustancialmente en los hospitales marítimos y militares. Si éstos se convirtieron en modelo, en punto de partida de la reorganización hospitalaria, fue porque, con el mercantilismo, las reglamentaciones económicas se hicieron más estrictas y también porque el «precio del hombre» aumentaba cada vez más. Precisamente en esa época, la formación del individuo, su capacidad y sus aptitudes, empiezan a tener un más alto precio para la sociedad ${ }^{43}$.

El Reglamento es indicio del incremento progresivo de una sensibilidad hacia la institución en los círculos ilustrados europeos y americanos, que pretendía disminuir gradualmente su acción caritativa y volverlo un espacio más orientado por el saber médico, más competente para curar las enfermedades. Este conjunto normativo constituye también un elemento de estabilidad y autoridad, fomentado para imponer disposiciones uniformes. En él se repiten varios de los temas que habían dominado los proyectos de política hospitalaria desde el siglo XVI pero cuya urgencia se acrecienta en el siglo XVIII, tanto en Europa como en América: coinciden en afirmar la necesidad de más intervención civil y médica en la institución; en proponer nuevas formas de distribución del espacio; en formular una modalidad distinta de administración que diera lugar a menos abusos; en plantear una relación más estrecha entre alimentación, higiene y curación, entre otros aspectos.

El texto está dividido en un preámbulo y tres partes. El preámbulo sirve de introducción a las partes normativas, allí se establecen los propósitos generales y la justificación del Reglamento. En la primera parte, el plan trata sobre las funciones del personal del hospital, tanto del administrativo (contralor, comisario de entradas, mayordomo, capellán), como del médico (médico, cirujano

\footnotetext{
${ }^{41}$ Condorcet, 1977: 110-114.

${ }^{42}$ Granshaw y Porter, 1990: 150. Porter, 1995: 5-26. Foucault, 1978: 20.

43 Ibidem: 24.
} 
mayor, boticario mayor y subalterno, practicante mayor y menores, ropero, cabo de sala). La segunda parte se dedica a la descripción de las diferentes actividades hospitalarias de cuidado (visita del médico y del cirujano mayor en la mañana y en la tarde; las prevenciones de los facultativos que administran unciones) y de las diligencias para la asistencia espiritual de los enfermos. En la tercera parte se explican las dietas (composición), regímenes y raciones que debían darse a los enfermos según sus dolencias. Estos aspectos se estudiaran a continuación.

\section{PreÁmbUlo}

El Reglamento mandaba acciones específicas, «de indispensable observación», que exponían lo que se suponía era el correcto funcionamiento de la institución en diversos aspectos: personal dedicado al cuidado, rutinas hospitalarias, orden, alimentación, disciplina y normas de sociabilidad en el interior de la misma ${ }^{44}$. Buscaba además enmendar y «cortar de raíz» las pugnas que se presentaban entre los padres hospitalarios y los funcionarios de la Corona, sobre la administración de la institución y el tratamiento dado a los enfermos que allí se recibían. Se pretendía entonces «proceder al remedio de las faltas y a la corrección o castigo del que incidiere en ella por culpa de omisión o comisión». La queja respecto a las irregularidades, arbitrariedades y abusos cometidos en/ con los hospitales se escuchaba frecuentemente en toda la América española ${ }^{45}$.

Como se ha indicado, el hospital es objeto de intereses diversos y está atravesado por múltiples debates. Esta institución es un terreno de tensiones entre el poder religioso y el civil, en virtud de la acentuada orientación regalista de la monarquía borbónica, que pretendía contrapesar la notable influencia económica, política, social y sanitaria del estamento religioso en la sociedad de entonces ${ }^{46}$.

Las autoridades civiles aspiraban a intervenir de manera más eficaz en lo que podría llamarse «la asistencia sanitaria» en las Indias, la cual estaba profundamente vinculada con las políticas ilustradas de los borbones en relación con la pobreza y el crecimiento económico. Además, la convicción de ciertos funcionarios ilustrados de que algunas comunidades religiosas, como la de San Juan de Dios, no tenían competencia en asuntos administrativos,

${ }^{44}$ Reglamento para el gobierno interior..., 1776: 2.

45 Para el caso de la Nueva Granada, ver Alzate Echeverri, 2012. Restrepo Zea, 2006. Restrepo Zea y Escobar, 2006. Para el caso de la Nueva España: Alberro, 2005. Ranero Castro, 2003. Hernández-Saenz, 2000: 21-35. Para Puerto Rico: Crowe, 2012.

${ }^{46}$ Alzate Echeverri, 2012b: 195-196. 
llevó a que se cuestionara el gobierno de los hospitales que estaban bajo su cuidado, tildándolo de irregular, negligente, despreocupado $\mathrm{y}$, en ocasiones, incluso, abusivo, como se puede leer entrelíneas en el presente Reglamento.

Probablemente la redacción del Reglamento se fundó en el conocimiento previo de las falencias, errores y desaciertos que se presentaban en el funcionamiento de la institución, que N. J. Rapún había observado tras varios años de presencia en la isla. De ahí que, como cualquier conjunto normativo, viene a posteriori, con el fin de subsanar las dificultades de funcionamiento y de organizarlo de manera tal que fuera más ordenado y eficiente, buscando adecuar los medios disponibles a los objetivos pretendidos. De ahí también que el énfasis que se nota en el Reglamento sobre ciertos temas esté en relación, quizá, con la frecuencia e intensidad de problemas concretos en la institución.

En el proemio está claramente expresado a quiénes debería recibir el hospital de Cuba para su «curación»: tropas, forzados y «negros esclavos de $\mathrm{Su}$ Majestad». Era ésta una población que requería especial atención y cuidado. Más, si se tiene en cuenta que en Cuba, desde 1763, después de la invasión inglesa, la Corona aumentó la guarnición fija, que pasó de 1.800 a 4.000 hombres ${ }^{47}$. Además, durante la segunda mitad del siglo XVIII, sólo en La Habana laboraron unos 4200 esclavos y no menos de 2000 forzados en casi 26 años de construcciones militares ${ }^{48}$.

También en el introito se halla un objetivo que se repite, en forma diversa, en varios de sus apartes interiores, constituyéndose en uno de sus leitmotiv: la necesidad de «adaptación» de este conjunto de normas a la las «circunstancias, temperamento y costumbres del país». La preocupación por la necesaria «adaptación» de las reglas a unas condiciones locales específicas, que es visible desde el inicio del proceso de colonización, es clave para entender el espíritu de este Reglamento y para comprender algunos aspectos de la actitud hacia la ley en la América española, entre otras cosas.

La idea propuesta por el Reglamento era que éste se empleara para establecer relaciones entre lo observado, lo conocido, entre lo aprendido localmente y lo leído y sugerido. En este sentido, se aprecia una actitud que aconsejaba una aproximación a los problemas que debería ser a la vez metódica, empírica y teórica. Un acercamiento fundado en la observación, la experiencia, la práctica, antes que en la aplicación ciega o mecánica de lo que mandaba el texto $^{49}$. Se volverá sobre esto posteriormente.

\footnotetext{
47 Parcero Torre, 2005: 101-116.

48 Pérez Guzmán, 1992: 375.

49 Respecto a esta actitud de adaptación entre lo leído y lo observado, en otro contexto, ver Alzate Echeverri, 2005: 227.
} 


\section{PRIMERA PARTE: EMPLEADOS, FUNCIONES Y RESPONSABILIDADES}

La primera parte del Reglamento (artículos 1-97) proyecta una estructura hospitalaria que tendría tres grupos de trabajadores: el personal encargado de la asistencia y del cuidado del enfermo, la administración y los empleados dedicados a labores que hoy podrían calificarse como más «domésticas». Las actividades y obligaciones de cada uno de ellos estarían claramente precisadas, orientadas por criterios de orden, disciplina y subordinación, lo que permitiría determinar responsabilidades en caso de omisión o contravención.

Las constituciones de algunos hospitales establecidos en América consagraban ya varias de las disposiciones que ordenaba este Reglamento en relación con los grupos de personas que deberían laborar en la institución, incluso es posible confirmar que ciertos hospitales contaban, efectivamente, con un personal de asistencia significativo, un personal de dirección y de administración y otro encargado de algo que puede llamarse «servicios u oficios generales». El personal del Hospital San Juan de Dios de Santafé o el de Cartagena de Indias en 1763 no estaban muy lejos del ordenado por el Reglamento. Asimismo, las constituciones de los hospitales de Coro y de Trujillo (Venezuela, 1623), las del hospital de Manila (Filipinas, 1640), también registran la lista de empleados que tendría dichas instituciones, cercana a la propuesta por el Reglamento, aunque no es posible afirmar nada sobre su observancia ${ }^{50}$.

Siguiendo el Reglamento, el personal administrativo debería estar integrado por un contralor, un comisario de entradas y un mayordomo. El personal de atención directa a los enfermos, por un médico, un cirujano mayor, un boticario mayor y dos subalternos, un practicante mayor y varios menores, y algunos enfermeros -aunque sólo son mencionados tangencialmente-. Habría también un capellán para el consuelo y el acompañamiento religioso de los enfermos; y en el último rango de empleados, se tendría el ropero y al cabo de sala.

Las mayores responsabilidades del hospital le corresponderían al contralor, quien debería conocer a cabalidad el Reglamento y hacerlo cumplir, vigilando que cada uno realizara las acciones que le competían, cuidando la economía de la institución. Asimismo, autorizaría y examinaría los gastos de diferente índole que precisara el hospital (alimentos, utensilios, instrumentos, ropas); supervisaría el aseo de ropas, instalaciones y la buena dotación de la institución; determinaría responsabilidades en caso de que faltaran o se estropearan materiales. Pero además inspeccionaría la alimentación, la entrada y salida de

${ }^{50}$ Alzate Echeverri, 2012b: 65-66. Archila, 1966: 191. AGI, Patronato, 25, R. 49, Constituciones del hospital de Manila (1640). 
enfermos; su adecuada asistencia físico-espiritual; y vigilaría el correcto comportamiento de los empleados y los enfermos. El apoyo espiritual y sacramental del enfermo fue un aspecto inherente a la labor hospitalaria hasta el siglo $\mathrm{XX}$, vinculado a una concepción de la salud que unía el cuerpo y el alma ${ }^{51}$.

El comisario de entradas, estaría obligado a realizar listas de todos los enfermos que ingresaran y salieran, registrando el grupo poblacional al cual pertenecía, y obedecería «todas las órdenes» del contralor, para la mejor marcha del hospital. Mientras que el responsable de «proveer todo lo necesario para el hospital» sería el mayordomo. Éste debía informar a la Real Hacienda de lo que tuviere la institución, de lo recibido por diversos rubros (noveno de diezmos, donaciones de particulares, limosnas, aportes de la Corona); relacionaba los alimentos y utensilios que se gastaran cada mes, presentando cuentas claras en fechas específicas; cuidaría el aseo y correcto funcionamiento de la cocina, lavandería y despensa para evitar sanciones del contralor y supliría las ausencias del comisario de entradas y del contralor.

El apoyo espiritual de los enfermos estaría a cargo de un religioso que servía a la institución, un capellán, quien tenía como función consolar a los enfermos, explicar la «doctrina cristiana» a enfermos y empleados ${ }^{52}$, y acompañar a los agonizantes para que lograran una «buena muerte». Al mismo tiempo que atendería en confesión a los enfermos cuando entraban, les ofrecería la eucaristía y hacía una visita general dos tardes en la semana. Este eclesiástico no podía ausentarse sin dejar un suplente, con el fin de que siempre hubiera alguien que pudiera socorrer religiosamente a los enfermos. Desde muy temprano en su evolución, el objetivo los hospitales era lograr el bienestar físico y espiritual de los pobres enfermos; por ello, los internados en la institución fueron vistos como miembros de una nueva comunidad espiritual, que vivía transitoriamente en un locus religiosus ${ }^{53}$.

Pero el Reglamento sugería que fuera en torno a la figura del médico que girara una buena parte de la actividad hospitalaria. Se buscaba que él controlase todos los espacios del hospital, pues se veía como una autoridad de saber, que tendría la obligación de realizar las visitas de rutina (dos veces al día) ${ }^{54}$, supervisar los alimentos, vigilar la naturaleza, buena calidad y dosis de los remedios dados a los enfermos; separarlos según el tipo de dolencia que

${ }^{51}$ Courtenay, 2007: 77-106.

52 «Si fueren negros no bautizados, se les enseñará con particular amor, y cuidado para ponerlos en aptitud de recibir aquel Santo Sacramento», Reglamento para el gobierno interior..., 1776: 11.

${ }^{53}$ Risse, 1999: 106.

${ }^{54}$ En verano a las 5 am y 3 pm; en el invierno 6 am y 2 pm. 
padecieren, acudir al llamado de los enfermos cuando éstos lo necesitaren, incluso fuera de las horas estipuladas para las visitas diarias. También debía mantener buenas relaciones con el barbero-cirujano, ordenarle las operaciones que éste ejecutaría ${ }^{55}$; y asignar las dietas a los enfermos según «el estado de la enfermedad, su carácter y circunstancias». Una mención especial merece la acción del médico en relación con las dolencias venéreas -posiblemente una de las que más recibían en el hospital- como se tratará más adelante. Sin embargo el médico aquí no participaría en la gestión o administración del hospital -como buscaría hacerse después- ya avanzado el proceso de medicalización de la institución a finales del siglo XIX.

Mientras que el cirujano mayor debería visitar tanto a los enfermos en las horas señaladas, en orden y silencio, como vigilar su correcto cuidado (en cuanto a alimentación, ropas y medicamentos). Orientaría, enseñaría y compartiría con los practicantes su saber en el oficio; dirigiría el suministro de unciones (unturas mercuriales utilizadas en el tratamiento del mal gálico) y estaría alerta a la separación de los enfermos por dolencias, reservando los «gálicos» a la sala de humor «venéreo». Consultaría las operaciones de cirugía graves (trepanaciones, amputaciones) y la disección de cadáveres con el médico. Es importante tener en cuenta que la diferencia entre médicos y cirujanos en la época se refiere a las distintas clases de enfermedades que cada una de ellas trataba. La cirugía sólo se aplica a las enfermedades externas (exteriores o quirúrgicas), aunque posee «todos los conocimientos cuya reunión forma la ciencia que enseña a curar. La medicina posee igualmente esa ciencia aplicándola únicamente a las enfermedades internas» ${ }^{56}$.

En el siglo XVIII, «la cirugía» se vuelve una «actividad clínica» en el pleno sentido de la palabra: la observación de los síntomas se vincula con el conocimiento de la enfermedad y se pone al servicio del diagnóstico y de intervenciones manuales más eficaces. La enseñanza de la cirugía se une a la de las otras ramas de la medicina ${ }^{57}$.

En relación con las «operaciones de cirugía», las había muy numerosas y variadas, por ello es necesario diferenciar la pequeña de la gran cirugía. La primera era una «forma elemental», practicada por todos los cirujanosbarberos, por ejemplo: incisiones de abscesos, cauterización, aplicación de

${ }^{55}$ Para que, en caso de que alguna «enfermedad de cirugía» se llegase a complicar con una de «medicina» procedieran en forma concertada, sin conflicto, Reglamento para el gobierno interior..., 1776: 13.

${ }^{56}$ Ballano, 1806, vol. 2: 409-410.

57 Grmek, 1996, vol. 2: 247. 
ventosas $^{58}$, curaciones de llagas y úlceras, drenajes, suturas, reducción de fracturas, extracción de dientes, sangrías y asistencia en algunos partos. En cuanto a «la gran cirugía», comprendía operaciones como las amputaciones, trepanaciones y cesáreas. Varias de estas intervenciones, bien fuere de pequeña o de gran cirugía, eran peligrosas a causa de sus graves complicaciones: infecciones (septicemias o gangrenas), hemorragias, además de la intensidad del dolor y de los estados de shock que provocaban ${ }^{59}$.

Hasta el siglo XVIII, la estancia hospitalaria no formaba parte oficial, sistemática, metódica de la educación que se daba a los médicos en las cátedras universitarias, aunque allí sí se llevaban a cabo por lo menos desde fines del Medioevo, actividades informales de enseñanza, impartida por algunos médicos, monjes herbolarios o cirujanos ${ }^{60}$. Así, el aprendizaje de la medicina, la cirugía, la farmacia, en el seno de la institución hospitalaria no era nuevo. Desde el siglo XVI eminentes médicos y cirujanos afiliados a hospitales, llevaban sus propios aprendices a visitar a los enfermos en su cama, para facilitar el aprendizaje, pero la mayor parte de la instrucción fue muy informal y asistemática ${ }^{61}$. En el siglo XVII se alentaba a los cirujanos españoles validados a «dar doctrina» allí, y de vez en cuando "se hace anatomía para mejor enseñanza» ${ }^{62}$.

El boticario mayor era concebido como una pieza clave en el funcionamiento del hospital, pues con los medicamentos bien elaborados y suministrados «se auxilia a la naturaleza, para que venza y extermine las enfermedades». El boticario «no dejará pasar el tiempo en que deben recogerse los medicamentos simples del país, como son los vegetales, las flores, frutos, yerbas (sic) simientes, cortezas, resinas, gomas y palos; y los animales, cuando están más sanos y nutridos», prepararía los medicamentos con cuidado y tiempo, para que no se fermenten y pierdan. Estas indicaciones eran importantes y su repetición en varias partes sugiere que podía constituir un problema frecuente en el hospital. Desde el siglo XIV existieron sistemas de inscripción en los envases de los

${ }^{58}$ Las ventosas eran instrumentos de cirugía. Una especie de vaso, por lo regular de vidrio, angosto de boca y ancho de barriga, que calentándose con estopas encendidas se aplica a algunas partes del cuerpo para atraer con violencia los humores viciados al exterior.

${ }_{59}$ Las operaciones más complicadas provocaron una altísima tasa de mortalidad hasta mediados del siglo XIX, cuando se formalizan una serie de principios de cirugía fundamentales: los de la anestesia general (1847) mediante el empleo del éter o el cloroformo, los de la anestesia local (1860), gracias al uso de la cocaína como tópico, y los trabajos de Lister (a partir de 1867), sobre los postulados básicos de la antisepsia en la práctica quirúrgica. Grmek, 1996, vol. 2: 230.

${ }^{60}$ Lindemann, 1999: 160-161.

${ }^{61}$ Risse, 1999: 252.

${ }^{62}$ Huguet-Termes, 2004: 280. Ver asimismo: Huguet-Termes, Arrizabalaga y Cook, 2009. Faure, 1979: 281. 
boticarios donde se determinaba el momento de elaboración y de caducidad del remedio, así como las dosis que debían administrarse ante cada dolencia. Estos rótulos eran obligatorios y servían a los visitadores de los hospitales para verificar el buen estado y la legalidad de los productos que se consumían en la institución. También debería solicitar al jefe los instrumentos y materias que necesite para elaborar los medicamentos en cantidades necesarias, «elegirá un sitio capaz para el laboratorio», así, el deseo de tener un laboratorio indica que buscaba dársele al hospital un grado importante de medicalización.

Los boticarios subalternos preparaban los medicamentos para suministrar a cada enfermo según las indicaciones médicas y anotaban las dosis y horas en un cuaderno, con el fin de evitar confusiones y malas administraciones. Entretanto, el practicante mayor era quien, por tiempo específico, se instruía en la práctica de la cirugía y medicina, al lado y bajo la orientación de un facultativo. Seguía las órdenes del contralor, el cirujano y el médico. Tendría a cargo las actividades de los practicantes menores, podría reprenderlos en caso de desobediencia. Estos últimos estaban encargados de hacer las curaciones que les mandaren (sangrías, vejigatorios, cataplasmas, enemas, gárgaras, entre otros), es decir, «todo lo perteneciente a los tópicos».

En el último escalón del personal de servicio estaba el ropero y el cabo de sala. Al ropero le correspondían múltiples funciones, que iban más allá de las que su nombre puede sugerir. Recogía las ropas del enfermo cuando éste entraba en el hospital, anotando su nombre en una papeleta que cosería sobre sus prendas. Le ofrecía su ropa de cama, se encargaría de revisar y sugerir la actuación de los practicantes en las curaciones, supervisaría el correcto lavado de las ropas, sábanas y cochones por el lavandero suministrándole jabón, lejías y demás elementos necesarios, todo con una papeleta donde se registrara tanto lo entregado, como lo recibido. Cuidaba, además, de que no se mezclaren las ropas de los enfermos de una sala con los de otra para «prevenir el contagio».

El cabo de sala estaba vinculado con la supervisión de labores domésticas muy variadas, que deberían ejecutar los enfermeros: barrer y mantener aseadas las salas, los vasos y los utensilios de que se sirven los enfermos; poner sahumerios para desodorizar, servir las comidas a los enfermos; estimar cuando debían recibir el sacramento de la extrema unción: vigilar que nadie introdujera comidas o bebidas, de cualquier naturaleza, al hospital; que no hubiera juegos, que no se formaran corrillos que perturbaran la paz y que no hubiera dos personas en una cama. La individualización del lecho hospitalario había ido imponiéndose en forma lenta durante el siglo XVIII, lo que iba a permitir progresivamente, además, el seguimiento individual del enfermo.

El personal proyectado para el hospital también muestra que allí se debían llevar a cabo distintas prácticas médicas y que en ocasiones coexistían en el 
lugar diversas tradiciones terapéuticas; el hospital era, asimismo, un espacio de «adaptación» de los usos curativos de las plantas, minerales o animales locales a las necesidades de la población que allí se curaba.

Hay una especificación en este documento que se articula con el interés creciente de la Corona por garantizar la existencia de un soporte para la efectiva gestión y de una herramienta para la administración: la obligación de tener registros escritos de las dinámicas de la vida hospitalaria (diversos cuadernos con anotaciones sobre cada enfermo, formularios de entradas, de salidas, papeletas de cuentas). Este interés por la expansión del registro escrito en el hospital ha sido interpretado a menudo como signo de un deseo de control, inspección y vigilancia dentro del largo y sinuoso proceso de medicalización del hospital, lo que puede no ser del todo falso. Sin embargo, es interesante plantear que el escrito sirve para estructurar y para producir conocimiento, contribuye a la organización de los comportamientos dentro del establecimiento y produce rutinas; generando así la formalización de prácticas juzgadas necesarias para la buena marcha de la institución.

\section{SEGUNDA PARTE: DINÁMICAS Y USANZAS HOSPITALARIAS}

La siguiente parte (artículos 98-124) se dedica a explicar la manera como los médicos, cirujanos y boticarios realizarían las visitas a los enfermos. El artículo 109, por ejemplo, especifica cómo habrían de ejecutarse las unciones (método terapéutico empleado para tratar las afecciones sifilíticas), lo que supondría su alta incidencia en el hospital de aquel entonces. Y entre el 110 y el 124 se especifican los utensilios, la forma de los colchones y almohadas; la naturaleza de las cosas que deberían darse al enfermo tales como: sábanas, frazadas, ropas, plato, taza, cuchara, servilleta, lamparita y camisones. Se determina también la distancia ideal que debería existir entre las camas para permitir la aireación y la más cómoda visita de los facultativos. Se observa además la necesidad de establecer las formas correctas de actuar en los distintos momentos de la vida hospitalaria: el ingreso de los enfermos, y su acomodamiento; las visitas de médico, cirujano, boticario; las rutinas de alimentación, de limpieza y aseo, de sueño y vigilia, entre otras.

Tras la llegada del médico al hospital -en la mañana y en la tarde- se darían tres golpes de campana, lo que advertiría al boticario, a un practicante de cirugía, a un cabo de sala y a un enfermero que deberían acompañar al médico en su visita. De nuevo aparece aquí la importancia de la escritura para la efectiva gestión de la vida hospitalaria. El cabo de sala debería escribir en un cuaderno todas las observaciones del médico sobre la alimentación que debería 
darse al enfermo (tipo de alimento, preparación, raciones); el boticario, en otro cuaderno, registraría lo que el médico mandare sobre los medicamentos que debían administrarse; la misma tarea realizaría el practicante de cirugía, quien anotaría, en otro cuaderno, las curaciones de cirugía -sangrías, cataplasmas, emplastos, ventosas- que el médico ordenare. Al final de la visita, el médico firmaría cada cuaderno.

La visita del cirujano mayor también se realizaría dos veces al día. Lo acompañarían las personas que ocuparen las funciones que antes se anotaron en relación con la visita médica y realizarían las mismas anotaciones en sus respectivos cuadernos, con el fin de que se tuviera información clara sobre el tratamiento dado a cada enfermo y de que se pudiesen confrontar equivocaciones o errores y establecer responsables. Al terminar la visita, el cirujano firmaría cada cuaderno.

El personal de asistencia trataba a enfermos de mal gálico-hoy llamado sífilis-(y a personas con diversas dermatosis que hoy tienen variadas denominaciones), con ayuda de fricciones mercuriales. Durante mucho tiempo este método fue considerado el tratamiento más eficaz y rápido. $\mathrm{El}$ procedimiento general de este remedio era el siguiente: el enfermo a quien se aplicarían las fricciones debía tomar un baño en la mañana, y en la tarde se le hacía la fricción con un ungüento mercurial. Se comenzaba por embadurnar una de las piernas, desde el tobillo interno y la parte inmediata de la planta del pie hasta la rodilla.

Esta operación duraba alrededor de media hora, después de lo cual se acostaba al enfermo. A los dos días se le prescribía, igualmente, un baño general o lociones según el estado de las fuerzas del paciente, pero la fricción se le hacía en el muslo, luego desde la rodilla hasta cerca del escroto; el sexto día en el antebrazo, el octavo en el brazo y los días siguientes en las extremidades. Los enfermos debían cubrir estas partes a medida que iban recibiendo las fricciones con lienzos o trapos que deberían tener puestos noche y día, para mantener la untura. La recurrencia con que se hacen anotaciones sobre las «unciones» sugiere la frecuencia con la cual debían tratar esa dolencia en el hospital, adonde acudían los hombres de la armada, los esclavos y los forzados, población muy afectada por ese mal, aunque los retos que suponía el tratamiento a tal enfermedad en los hospitales tuvieron que ser enfrentados desde los primeros tiempos de su implantación en América ${ }^{63}$.

${ }^{63}$ Sobre la polémica del origen del mal venéreo, ver: Livingstone, 1991: 587-590. Stirland, 1994:53-54. Quétel, 1986. 
La reglamentación buscaba establecer así una regularidad en los horarios de los enfermos y en las funciones de los empleados; pretendía que las órdenes médicas inspirasen mayor respeto, habida cuenta de lo difícil que ello podría ser en un lugar de sociabilidad como el hospital. Para la uniformización del modo de funcionamiento del hospital se necesitaba una aplicación permanente y regular de cada precepto.

\section{LIMPIEZA Y SALUD}

Entre los aspectos significativos de este plan se encuentra la importancia que se le concede al aseo en relación con la salud en varios apartes. El plan aconseja seguir continuamente varias normas de higiene: separación, ventilación, lavados diferenciados, limpieza de camas, lugares, ropas e instrumentos, con el fin de conjurar el contagio. Esta reglamentación testimonia una concepción de la limpieza que operó hasta principios del siglo XIX, que estaba centrada sobre las manos, la cara y la ropa. Por eso se predicaba el cambio de esta última cada cierto tiempo y se velaba por su blancura. La limpieza no tenía nada que ver con el aseo de todo el cuerpo. En este documento, como en otros de la época que evocan el aseo del hospital, hace alusión a la limpieza de los espacios, "las inmundicias, la basura» y las ropas de la cama y de los enfermos ${ }^{64}$.

El Reglamento trata sobre la necesidad de la limpieza y el aseo en el proemio y luego, cuando trata sobre las funciones de varios empleados. Por ejemplo, al presentar las tareas del contralor, en el artículo 7, señala: «celará se traten los utensilios con el mayor cuidado, esmero, y aseo [...], como igualmente la ropa u otra cosa que se pierda por falta del debido aseo». Repite luego esta indicación:

Impenderá el mayor cuidado, y esmero en que el Hospital esté aseado en todas sus partes, por ser uno de los asuntos principalísimos para conservar, o restaurar la salud, sobre lo que si se advirtieren faltas por disimulo o tolerancia a los dependientes, se considerarán suyas ${ }^{65}$.

Asimismo, al anotar las tareas del mayordomo, menciona: «cuidará del buen aseo y disposición de la cocina, despensa, panadería y lavandería». Y posteriormente: «cuidará [...], de que las cosas que se hallan a su cargo, estén

\footnotetext{
${ }^{64}$ Sobre la historicidad de las prácticas de limpieza, ver Vigarello, 1985.

${ }^{65}$ Reglamento para el gobierno interior..., 1776: 6.
} 
bien custodiadas, aseadas y resguardadas». Indicaciones semejantes realiza de nuevo en los artículos 38 y $111^{66}$.

Esta organización del espacio y del personal hospitalario estaría al servicio de una sencilla disciplina institucional. En principio, cada individuo debía tener su lugar. Por ello se aconseja instaurar sistemas para verificar el número de enfermos y su identidad; se reglamentan sus idas y venidas; se les obliga a quedarse en su sala; se coloca un número en cada cama; se aísla a los moribundos y a los que sufren de enfermedades contagiosas. Se manda la separación de las camas y los cuerpos - de nuevo-, y se propugna porque la atención médica comience a ejercerse más fuertemente sobre las enfermedades y sobre el contagio. Es posible ver también, en este deseo de separación, el sentimiento religioso que pretende combatir los juegos y las tentaciones de la carne e impedir el contacto entre los sexos. Algunos autores han señalado la articulación de tal regla con los intereses religiosos de la institución, por su afán de hacer reinar un cierto orden moral y un importante papel espiritual. Es preciso recordar que no es ésta una norma que aparece en el siglo XVIII, pues estaba ya presente en algunas de las más tradicionales bases de reglamentación hospitalaria de la historia de la Iglesia, como las establecidas en 1585, junto con las disposiciones relativas a la instrucción religiosa y al establecimiento de libros detallados sobre los enfermos que ingresaban al hospital; sin embargo, en el siglo XVIII, con la necesidad de reforma de la institución hospitalaria, estas normas se revitalizan y aparecen con una renovada fuerza ${ }^{67}$.

\section{TERCERA PARTE: LA ALIMENTACIÓN}

La alimentación, por otro lado, es considerada en los artículos 125 a 157 del Reglamento. Aparecen allí distintos tipos de dietas, raciones, regímenes y reparos.

La ración (o dieta) básica, es la alimentación general que ofrecía la institución a los enfermos, comprendía «carne de vaca»-con o sin hueso-, tocino, garbanzos, pan y manteca de puerco. A ella se añadían, en ocasiones, según las necesidades de los dolientes, porciones de determinados alimentos o preparaciones que acompañaban la dieta básica. Estas podían ser de gallina, de pichón, de pollo, de albóndigas, de picadillo, de huevos, de arroz, de fideos,

\footnotetext{
${ }^{66}$ Ibidem: 9, Artículos 28 y 30.

${ }^{67}$ Alzate Echeverri, 2007: 51-72.
} 
de sopa, de atole -de harina y de arroz-, de chocolate, de vino y de leche ${ }^{68}$. La alimentación apuntada a los enfermos era simple.

También se señalaban los regímenes, es decir, la alimentación que se hacía en función de ciertas dolencias específicas, como el régimen de purgados; y los reparos, o alimentos reconfortantes que proporcionaban a los enfermos para darle vigor: «reparo para el estómago», «reparo extraordinario».

Los españoles introdujeron en Cuba el ganado vacuno, mular y porcino. Este ganado se criaba en hatos, haciendas y en potreros, en pequeñas y grandes explotaciones. La isla llegó a producir estos animales en tal cantidad que la carne de vaca y de cerdo se convirtió, por su bajo precio, en la base de la alimentación de toda la población cubana ${ }^{69}$. Además se comía mucho pan, probablemente de cazabe - realizado con la raíz de la yuca agria- o de maíz, y garbanzos.

La dieta básica que ofrecía la institución puede parecer curiosa si se analiza desde una sensibilidad contemporánea. Las diferencias que se perciben recuerdan hasta qué punto la alimentación considerada saludable es indisociable de un universo histórico, científico y mental determinado. La alimentación que se proponía para el hospital estaba limitada por un conjunto de circunstancias que determinaban qué se podía comer, y que pueden agruparse en económicas, de disponibilidad, religiosas y de «sanidad» (digerible fácilmente y no dañino) del alimento.

El acto de comer y sus rituales son históricos y culturales, son construcciones sociales ancladas en una historia. Los médicos y filósofos de la Antigüedad ubicaban la comida entre los elementos «no naturales». Hipócrates la incluyó entre los factores de la vida que no pertenecen al orden «natural», sino al «artificial», lo que sugiere que pertenece a la cultura, a aquello que el hombre construye y transforma.

La comida que se debería impartir en el hospital tenía características especiales en relación con el repertorio de alimentos que se ofrecía, la forma de prepararla, los momentos en que se daba y la manera como comían los diferentes enfermos y los distintos grupos que integraban la institución. Lo que se consumía en el hospital habla también de formas más o menos corrientes de consumo alimentario en aquella época en Cuba. La carne que se usaba en este tipo de instituciones de la isla, era el tasajo (carne salada, magra). Había

${ }^{68}$ La palabra atol o atole viene del náhuatl atollii, que significa aguado. Es una bebida caliente, hecha con harina de maíz o de arroz y disuelta en agua o leche, la cual se puede endulzar y se le pueden agregar otros ingredientes como cacao, miel o frutas.

69 Parcero Torre, 2005: 101-116. 
tasajo de primera, segunda y tercera categoría ${ }^{70}$, esta última era consumida por los esclavos y los pobres y quizás también en el hospital. El pan era probablemente de cazabe, el cual era el resultado de un proceso antiguo. Se extraía el jugo de la yuca amarga, y se usaban sus residuos para calentarlos hasta convertirlos en una torta sólida de variados tamaños ${ }^{71}$.

Al hacer una clasificación simple de los alimentos registrados, se puede tener una idea vaga de su valor, según sean grasas, proteínas y carbohidratos. Sin embargo, se observa que la alimentación era fundamentalmente energética, apta para obtener la fuerza necesaria para el restablecimiento del enfermo.

\section{UNA RETÓRICA DE LA ADAPTACIÓN}

Un leitmotiv del Reglamento es la necesidad de «adaptación» de ese conjunto de normas a las condiciones y posibilidades locales. El empleo del término «adaptación» sugiere una acomodación, un ajuste, un arreglo de lo que el texto manda, con el contexto, las circunstancias, las realidades y las costumbres de los territorios donde se debería aplicar.

Si bien desde finales del siglo XIX, después de los estudios de Charles Darwin, la palabra «adaptación» refiere muy frecuentemente a un proceso biológico evolutivo, y en otras ocasiones a la acomodación de un discurso a otro; un siglo antes, la adaptación se pensaba más en relación con una esfera retórica, filosófica y práctica. Desde el punto de vista retórico, está vinculada con la idea de conveniencia; desde una perspectiva filosófica, la adaptación se refiere a una actitud pragmática en el sentido de que las teorías deben adecuarse a los hechos y no al contrario ${ }^{72}$.

La adaptación como táctica en el proceso de conquista y colonización española en América ha sido explorada en diversas dimensiones. La administración colonial española pronto admitió que, una vez llegado a una nueva realidad, su discurso, sus instituciones, sus normas, perdían coherencia y, por ello, los esfuerzos se debían centrar entonces en intentar adaptarse a las circunstancias y situaciones que lo rodeaban.

Es el mismo espíritu del Reglamento, que tiene en cuenta expresamente las realidades locales en las cuales estaba inscrita la dinámica institucional. Se puede percibir la posibilidad de una «adaptación-negociación de la norma», desde la enunciación, aunque se ignoren sus efectos reales. Tal consideración

\footnotetext{
70 Sarmiento Ramírez, 2003: 218.

71 Serra Moreno, 2007: 104.

72 Lértora Mendoza, 1989: 395.
} 
lleva a pensar en el reconocimiento que hace este documento de una singularidad americana, lo que justifica la adaptación y no la aplicación ciega de lo que se hacía en Europa. Esto aparece muchas veces, enunciado de formas diferentes. Desde el principio, en el proemio se señala que los artículos de este Reglamento deben ser observados cuidadosamente «en cuanto sean adaptables a la isla de Cuba» ${ }^{73}$, es decir, con la condición de que puedan acomodarse a los usos, costumbres y prácticas de la isla. Más adelante reaparece la anotación:

Sera de su cargo [del cirujano del hospital] dirigir el método de ministrar las unciones, pedir al contralor todo lo necesario, acomodarse a lo que ofrece el país, y no intentar practicarlo bajo las mismas reglas que París, Mompeller (sic), y otras ciudades de Europa, porque la generalidad no puede observarse en todo su rigor, por la incompatibilidad del clima, y demás circunstancias a que es preciso acomodarse. $\left(\right.$ Art. 52) ${ }^{74}$.

Esta vez considera la adaptación de las normas del Reglamento al clima del territorio donde esperaba aplicarse. La cuestión del clima y su influencia en los seres humanos fue objeto de debates desde tiempos antiguos (Hipócrates, Aristóteles), pero tuvo una revitalización en el siglo XVI pues se convirtió en uno de los temas fundamentales de la literatura europea sobre la naturaleza americana y, en general, sobre el Nuevo Mundo ${ }^{75}$. Este interés por el clima se entiende porque el pensamiento ilustrado privilegió, entre otras, la reflexión relativa al control del hombre sobre la naturaleza, lo que significaba, la victoria de la «razón y de la civilización sobre la barbarie».

La preocupación específica por la relación clima-ley remite, en el siglo XVIII, a Montesquieu, en El espíritu de las leyes. El interés de Montesquieu por los temas climáticos está vinculado con cuestiones médicas y naturalistas. La medicina en el siglo XVIII afirmó una aproximación hacia lo vivo donde los preceptos de Hipócrates, expresados en su célebre tratado Aires, aguas y lugares, fueron claves. Con el clima como indicador de diversidad, Montesquieu complejiza el problema de las diferencias y da un nuevo sentido a los «climas», como lugares en los cuales se construye cierta manera de sentir. Su planteamiento, in fine, permite recusar toda caracterización universalista de la naturaleza humana. Para explorar el problema de las normas y sus efectos

73 «El Rey aprueba este Reglamento, y manda se imprima, tirándose cuatrocientos ejemplares, y se comunique à las demás partes de Indias, para la exacta observancia de todos sus Artículos, en cuanto sean adaptables con la Isla de Cuba [...]», Reglamento para el gobierno interior..., 1776: 14.

${ }^{74}$ Idem.

${ }^{75}$ Al respecto ver: Alzate Echeverri, 2007. 
plantea la necesidad de estudiar las leyes «en situación» (leyes situadas). La razón humana encarnada en la ley siempre «se aplica», es decir, no es uniforme, ella obra siempre «en situación» ${ }^{76}$.

Sobre la «adaptación» o la «conveniencia» de la legislación -en este caso del Reglamento- a las realidades locales, la obra de Montesquieu aporta más elementos de reflexión. Trata sobre la necesidad de producir leyes «adaptadas», más conformes a la naturaleza de los pueblos a quienes van dirigidas. El gobierno más acorde a la naturaleza es aquel cuya disposición particular se relaciona mejor con la disposición del pueblo para el cual se establece. Las leyes positivas deben ser «tan propias» al pueblo para el cual fueron dictadas, que las de una nación nunca pueden convenir a otra ${ }^{77}$.

La anotación de ser conforme al pueblo, al país, puede verse en diversos niveles. El artículo 53 consagra la necesidad de utilizar medicinas «arregladas» a lo que el país produce:

[El cirujano mayor] No recetará cosas que no hay, ni puede haber en el Hospital, porque no todos tienen igual disposición para trabajarlas, y se arreglará à lo que el país produce; bien que no omitirá lo que sea esencial para la unción, ni que propenda al alivio de los enfermos, pues todo se consigue con el buen gobierno, estudio, y aplicación del facultativo. (Art. 53) ${ }^{78}$.

Todo un vocabulario que hace eco a la conveniencia - «se arreglará », «se acomodará a lo que ofrece», «según las circunstancias, temperamento y costumbres del País», «en cuanto sean adaptables»-, sirve para guiar la puesta en práctica del Reglamento.

La observación de la norma sería producto de una negociación entre grupos que pueden compartir repertorios de convenciones diferentes (autoridades metropolitanas, autoridades locales). La negociación puede comprenderse como un cambio, que puede ser sólo de tono o de acento, un intercambio de visiones, con el fin de llegar a un acuerdo sobre la manera de ejecutar la norma.

\section{CONSIDERACIONES FINALES}

Es necesario tener claro que el Reglamento estudiado es una fuente oficial, que expresa sobre todo los anhelos e ideales de las autoridades metropolitanas, en relación con las reglas que debían seguirse en las instituciones hospitalarias.

\footnotetext{
${ }^{76}$ Montesquieu, [1758] 1995. Casabianca, 2013a.

77 Casabianca, 2013b.

78 Reglamento para el gobierno interior..., 1776: 15.
} 
No debe caerse en la tentación de tomar tales aspiraciones por realidades, de tomar el «deber ser» por el «ser».

Este documento muestra algunas ideas dominantes del siglo, vinculadas con la secularización, la utilidad, la organización y la adaptación. Y, de cierta manera, también deja ver repeticiones, reproducción de algunas normas que se mandaban una y otra vez desde el siglo XVI; así como situaciones y circunstancias perturbadoras y dañinas, que se presentaban permanentemente en la institución. A partir de los puntos en los cuales hace énfasis el documento, aquellos en que insiste y es reiterativo, pueden quizá vislumbrarse los aspectos que más entorpecían, a juicio de Rapún, su buen funcionamiento y de ahí su interés por transformarlos o erradicarlos. En forma sucinta, estas condiciones nocivas tenían relación con las peleas entre civiles y religiosos sobre la mejor manera de manejar el hospital, para el bien de los enfermos y de la Real Hacienda; con los gastos excesivos; el mal trato dado a utensilios e instrumentos de la institución; el desaseo en instalaciones, ropas, enfermos, enseres; el robo de materiales necesarios para el establecimiento (alimentos, ropas, objetos); la falta de responsabilidades cuando los empleados dañaban equipos o descuidaban sus funciones; la poca o nula asistencia espiritual a los pacientes; al mal comportamiento y costumbres de enfermos y sirvientes (embriaguez, escándalos, charlas inadecuadas); la escasez y mala calidad de los alimentos; la insuficiencia y mal estado de los remedios, entre otras.

Para evitar el contagio se buscaba la instauración sistemática de salas separadas según las enfermedades, camas individuales, establecimiento de espacios para la circulación del aire, utilización de sahumerios; también se planeaban actividades de tratamiento y cuidado a los enfermos (visitas diarias de médico, cirujano, boticario, indicaciones para las unciones, instrucciones para la alimentación). Desde el punto de vista administrativo (establecimiento de una jerarquía, instauración de responsabilidades claras para cada empleado, elaboración de registros escritos para conservar la información, para transmitirla y para determinar responsabilidades ante faltas o errores); de asistencia espiritual; todo debía observarse teniendo en cuenta criterios de conveniencia a los usos, costumbres y posibilidades locales.

El Reglamento para el gobierno interior consagra globalmente, una vez más, grandes principios básicos que debían regir la vida hospitalaria cubana y americana, reuniendo disposiciones antiguas con otras más recientes. La aparición sucesiva, cíclica de medidas de contenido más o menos semejante sobre el ideal del funcionamiento hospitalario estuvo motivada quizás por la dificultad para lograr su cumplimiento, en el caso de las reglas no observadas, y por las complicaciones para conocer en detalle la vida hospitalaria en sus vastos territorios y saber dónde y cuáles normas se respetaban y cuáles no. 
Les correspondería a las autoridades locales desarrollar todo un trabajo de comprensión y adaptación del Reglamento. Se enfatiza la necesidad de ofrecer mejores cuidados a los enfermos de los hospitales coloniales.

El Reglamento permite ver cómo el hospital es un elemento importante de la cultura local y de la vida urbana. Él contribuye, en la medida de sus posibilidades, a permitir el restablecimiento de un sector de la población colonial, participa de la construcción de cierto tipo de cohesión social y es también un lugar de poder.

\section{BIBLIOGRAFÍA}

Alberro, Solange, Apuntes para la historia de la Orden Hospitalaria de San Juan de Dios en la Nueva España, México, 1604-2004, México, El Colegio de México/ Orden Hospitalaria de San Juan de Dios, 2005.

Alzate Echeverri, Adriana María, "Manuales de salud en la Nueva Granada (17601810). ¿El remedio al pie de la letra?", Revista Fronteras de la Historia, 10 (Bogotá, 2005): 209-252.

Alzate Echeverri, Adriana María, Suciedad y orden. Reformas sanitarias borbónicas en la Nueva Granada, 1760-1810, Bogotá, Editorial Universidad del Rosario/ Instituto Colombiano de Antropología e Historia-Facultad de Ciencias Sociales y Humanas de la Universidad de Antioquia, 2007.

Alzate Echeverri, Adriana María, "Comer en el hospital colonial: apuntes sobre la alimentación en tres hospitales neogranadinos a finales del siglo XVIII", Revista Historia Crítica, 46 (Bogotá, 2012a): 18-42.

Alzate Echeverri, Adriana María, Geografia de la lamentación. Institución hospitalaria y sociedad. Nuevo Reino de Granada 1760-1810, Bogotá, Editorial Universidad del Rosario/Centro Editorial Javeriano, 2012b.

Amores Carredano, Juan Bosco, "Juan Ignacio de Urriza y la intendencia de la Habana (1776-1787)", Ronald Escobedo Mansilla, Ana De Zabala Beascoechea y Oscar Alvarez Gila (eds.), Euskal Herria y el Nuevo Mundo. La contribución de los vascos a la formación de las Américas, Vitoria, Servicio Editorial Universidad del País Vasco, 1996: 227-247.

Amores Carredano, Juan Bosco, "La renta de tabaco en Cuba a finales del siglo XVIII", Agustín González Enciso y Rafael Torres Sánchez, (eds.), Tabaco y economía en el siglo XVIII, Pamplona, Ediciones Universidad de Navarra, 1999: 123-137.

Archila, Ricardo, Historia de la medicina en Venezuela, Mérida, Universidad de Los Andes, 1966. 
Astrain Gallart, Mikel, "El Real Tribunal del Protomedicato y la profesión quirúrgica española en el siglo XVIII", DYNAMIS. Acta Hisp. Med. Sci. Hist. Lllus, 16 (Granada, 1996): 135-150.

Ballano, Antonio, Diccionario de medicina y cirugía o biblioteca manual médicoquirúrgica, vol. II, Madrid, Imprenta real, 1806.

Belaubre, Christophe, "El proceso de laicización de los hospitales en la capital del Reino de Guatemala (XVI-XX)", Revista Cambios y permanencias, 2/12 (Bucaramanga, 2011): 3-32.

Casabianca, Denis de, "Climats", Dictionnaire Montesquieu [en ligne], sous la direction de Catherine Volpilhac-Auger, ENS de Lyon, septembre 2013a. URL: http:// dictionnaire-montesquieu.ens-lyon.fr/fr/article/1376426454/fr.

Casabianca, Denis de, "Convenance", Dictionnaire Montesquieu [en ligne], sous la direction de Catherine Volpilhac-Auger, ENS de Lyon, septembre 2013b. URL: http://dictionnaire-montesquieu.ens-lyon.fr/fr/article/1376426454/fr.

Céspedes del Castillo, Guillermo, "América en la Monarquía”, Actas del Congreso Internacional sobre Carlos III y la Ilustración, vol. I, Madrid, Ministerio de Cultura, 1989: 91-193.

Céspedes del Castillo, Guillermo, El tabaco en Nueva España, Madrid, Real Academia de la Historia, 1992.

Condorcet, "Mémoire sur les hôpitaux", Dix-huitième siècle, Paris, Editions Garnier Frères, 1977: 399-409.

Courtenay, Lynn, "The Hospital of Notre-Dame des Fontenilles at Tonnerre: medicine as misericordia", Barbara S. Bowers (ed.), The medieval hospital and medical practice, Aldershot, Ashgate, 2007: 77-106.

Crowe, Monica Lynn, Rise of Public Works and Sanitation in San Juan, Puerto Rico, 1765-1823, Florida, International University, Electronic Theses and Dissertations, Paper 592, http://digitalcommons.fiu.edu/etd/592.

De los Reyes Leoz, José Luis, Madrid, laboratorio de pobres. Asistencia y control social en la corte de los Austrias, tesis de doctorado en Historia, Madrid, Universidad Autónoma de Madrid, 2003.

Faure, Olivier, "L'hôpital et la médicalisation au début du XIXe siècle: l'exemple lyonnais (1800-1830)", Annales de Bretagne et des pays de l'Ouest, 86/2 (Rennes, 1979): 277- 290.

Foucault, Michel, Surveiller et punir. Naissance de la prison, Paris, Gallimard, 1975.

Foucault, Michel, "La incorporación del hospital en la tecnología moderna", Educación Médica y Salud, 12/1 (Washington, 1978): 69-77. 
Foucault, Michel, “Conférence à 1'Université de Stanford, octobre 1979”, Hubert Dreyfus y Paul Rabinow y Michel Foucault, Un parcours philosophique, Paris, Gallimard, 1984: 195-207.

González Ripoll-Navarro, María Dolores, Cuba. La isla de los ensayos. Cultura y sociedad, 1790-1815, Madrid, CSIC, 1999.

Granshaw, Lindsay y Porter, Roy, The Hospital in History, New York, Routledge, 1990.

Grmek, Mirko D., "La main. Instrument de connaissance et du traitement", Mirko Drazen Grmek y Bernardino Fantini (dirs.), Histoire de la pensée médicale en Occident, vol. II, París, Le Seuil, 1996: 224-251.

Hernández-Saenz, Luz María, "Seamen, Surgeons and Empire: Spanish Naval, Medical Reform and Mexican Medicine in the Late Colonial Period", The Northern Mariner/Le Marin du Nord, X/1 (Ottawa, 2000): 21-35.

Huguet-Termes, Teresa, “'La mayor grandeza de la monarquía y el mayor blasón de Madrid'. Algunas reflexiones en torno a los opúsculos de Gregorio de Aldana sobre los reales hospitales (1661 y 1666)", José Martínez Pérez (coord.), La medicina ante el nuevo milenio: una perspectiva histórica, Ciudad Real, Universidad de Castilla-La Mancha, 2004: 271-185.

Huguet-Termes, Teresa, Arrizabalaga, Jon y Cook, Harold J. (eds.), Health and Medicine in Hapsburg Spain: Agents, Practices and Representations, Londres, The Wellcome Trust Centre for the History of Medicine at UCL, 2009.

Jori, Gerard, "La política de salud en el pensamiento ilustrado español. Principales aportaciones teóricas", Scripta Nova. Revista electrónica de geografía y ciencias sociales, XVI/418 (Barcelona, 2012): 1-29.

Kuethe, Allan J., and Inglis, G. Douglas, "Absolutism and Enlightened Reform: Charles III, the Establishment of the Alcabala, and Commercial Reorganization in Cuba", Past \& Present, 109 (Oxford, 1985): 118-143.

Kuethe, Allan J., Cuba, 1753-1815: Crown, Military, and Society, Knoxville, University of Tennessee Press, 1986.

Lafuente, Antonio y Peset, José Luis, "Militarización de las actividades científicas en la España ilustrada”, José L. Peset (ed.), La ciencia moderna y el Nuevo Mundo, Madrid, CSIC, 1985: 127-147.

Lafuente, Antonio y Valverde, Nuria, Los mundos de la ciencia en la Ilustración española, Madrid, Fundación Española para la Ciencia y la Tecnología, 2003.

Lavrin, Asunción, Sexuality and Marriage in Colonial Latin America, Nebraska, University of Nebraska Press, 1992.

Lértora Mendoza, Celina A., "Los estudios superiores rioplatenses y su función en la dinámica cultural”, Peset, José Luis (ed.), Ciencia, vida y espacio en Iberoamérica, Madrid, CSIC, 1989: 389-422. 
Lindemann, Mary, Medicine and Society in Early Modern Europe, 1500-1800, Cambridge, Cambridge University Press, 1999.

Livingstone, Frank B., "On the Origin of Syphilis: An Alternative Hypothesis”, Current Anthropology, 5/32 (Chicago, 1991): 587-590.

Montesquieu, De l'esprit des lois (1758), Paris, Éditions Gallimard, 1995.

Naranjo Orovio, Consuelo (dir.), Historia de Cuba, vol. I, Madrid, CSIC, 2009.

Parcero Torre, Celia, "La alimentación en Cuba en el siglo XVIII", Revista de Humanidades, 19 (Monterrey, 2005): 101-116.

Pérez Guzmán, Francisco, "Las fuentes que financiaron las fortificaciones de Cuba", Tebeto. Anuario del Archivo Histórico Insular de Fuerteventura, 5/1 (Canarias, 1992): 363-382.

Peset, José Luis, "Educación y ciencia en el fin del Antiguo Régimen”, José Manuel Sánchez Ron (comp.), Ciencia y sociedad en España, de la Ilustración a la guerra civil, Madrid, Ediciones El Arquero/CSIC, 1988: 20-21.

Porter, Roy, "Howard's Beginning. Prisons, Disease, Hygiene”, R. Creese, W. F. Bynum y J. Bearn (eds.), The Health of Prisoners, Amsterdam, Rodopi, 1995: 5-26.

Quétel, Claude, Le mal de Naples. Histoire de la syphilis, Paris, Laffont, 1986.

Ranero Castro, Mayabel, Orden y obediencia. Reglamento de hospitales militares (Veracruz-La Habana), Cuadernos de Trabajo, Instituto de Investigaciones Histórico-Sociales, Veracruz, Universidad Veracruzana, 2003.

Reglamento para el gobierno interior, político y económico de los hospitales reales, erigidos en la isla de Cuba, con destino a la curación de las tropas, forzados, y negros esclavos de S.M., según las circunstancias, temperamento, y costumbres del país. Formado por el señor Don Nicolás Joseph Rapún, Madrid, 1776.

Restrepo Zea, Estela, Historia clínica del hospital San Juan de Dios, 3 vols., Bogotá, CES, Universidad Nacional de Colombia, 2006.

Restrepo Zea, Estela y Escobar, Andrés M., Plan de dieta alimentaria del hospital San Juan de Dios. Santafé, 1790, Bogotá, Universidad Nacional de Colombia, 2006.

Ricuperati, Giuseppe, "Hombre de las luces", Vincenzo Ferrone y Daniel Roche (eds.), Diccionario Histórico de la Ilustración, Madrid, Alianza Editorial, 1997: 21-33.

Risse, Güenter B., "Medicine in the Age of Enlightenment", Andrew Wear (ed.), Medicine in Society: historical essays, Chicago, University of Chicago Press, 1992: 149-195.

Risse, Güenter B., Mending Bodies, Saving Souls. A History of Hospitals, New York/ Oxford, Oxford University Press, 1999.

Rivero Muñiz, José, Tabaco: su historia en Cuba, vol. I, La Habana, Instituto de Historia, 1964. 
Roche, Daniel, La France des Lumières, Paris, Fayard, 1993.

Santamaría García, Antonio, "Evolución económica, 1700-1959”, Consuelo Naranjo Orovio, (dir.), Historia de Cuba, volumen 1, Madrid, CSIC, 2009: 69-128.

Sarmiento Ramírez, Ismael, "Alimentación y relaciones sociales en la Cuba colonial”, Anales del Museo de América, 11 (Oviedo, 2003): 197-226.

Serra Moreno, Jesús María, Cuba: un pueblo nuevo. Herencias etnoculturales indígenas en la región oriental, México, UNAM, 2007.

Stirland, Ann, "The origin of syphilis in Europe: Before or after 1493?", International Journal of Osteoarchaeology, 4/1 ( New York, 1994): 53-54

Vigarello, Georges, Le propre et le sale. L'hygiène du corps depuis le Moyen-Âge, Paris, Editions du Seuil, 1985.

Vigarello, Georges, "L'hygiène des Lumières", Patrice Bourdelais (ed.), Les hygiénistes. Enjeux, modèles et pratiques, Paris, Belin, 2001: 29-40.

Vila Vilar, Enrique y Kuethe, Allan J. (eds.), Relaciones de poder y comercio colonial: nuevas perspectivas, Sevilla/Texas, Escuela de Estudios Hispanoamericanos de Sevilla/Tech University, 1999.

Fecha de recepción: 8 de abril de 2014 .

Fecha de envío de las modificaciones: 16 de noviembre de 2014.

Fecha de aceptación: 18 de noviembre de 2014. 


\section{Reiterate, adapt, negotiate: On the regulation of hospitals in Cuba (1776)}

This article examines the Reglamento para el gobierno interior, político y económico de los hospitales reales de Cuba (Regulations for the Political, Economic, and Internal Governance of Royal Hospitals of Cuba). These regulations were established by the Spanish Crown in 1776, first for Cuba and later for all of Spanish America. The document is key to understanding some of the projects that the Crown undertook in its hospitals in the Indies. It sought to provide a general structure within which hospitals were to be administered, and medical, nutritional, and spiritual care were to be provided. The new standards reaffirmed, but also strengthened and intensified, existing policies. In addition, they sought to resolve a series of debates and disputes among different social groups about how the hospitals should be run.

KEY WORDS: History of Cuba; eighteenth century; colonial hospitals; medicine and assistance; public health. 